\title{
An Advanced Teaching Lab for the Setting up of an Islanded Production Unit
}

\author{
André Hodder and Basile Kawkabani \\ Ecole Polytechnique Fédérale de Lausanne EPFL, Electrical Machinery Group, Lausanne CH-1015, Switzerland
}

Received: December 06, 2012 / Accepted: February 19, 2013 / Published: August 31, 2013.

\begin{abstract}
The present paper addresses an advanced teaching lab consisting of setting up an islanded production unit. This teaching lab takes place in the very last semester at master level for students in electrical engineering with energy specialization. The purpose of this teaching lab is to combine knowledge learned in different areas such as power electronics, control, electrical machines and networks, and make use of all of them in practice. The present paper describes in detail the different steps followed by the student to set up an islanded production unit.
\end{abstract}

Key words: Teaching laboratory, islanded network, DC motor speed control, synchronous generator voltage control.

\section{Introduction}

This paper addresses an advanced teaching lab taught to electrical engineering master students, specialized in energy, taking place during the last semester of studies.

As explained in Ref. [1], many universities worldwide are putting efforts in renewing or reviving power engineering teaching labs. Over the past 10 years, many papers have been published addressing such teaching laboratories [2-10].

Here at the Ecole Polytechnique. Fédérale de Lausanne-EPFL [11], the curriculum for students in electrical power engineering contains many teaching labs related to power systems (Fig. 1) either for bachelor level students who need to learn the basics of electromechanical systems and drives, up to advanced teaching labs at master level.

The present paper focuses on the advanced teaching lab given to electrical power engineering students at master level.

The teaching lab presented lasts a whole semester,

Corresponding author: Basile Kawkabani, Ph.D., senior scientist, research fields: modeling of power systems, power system stability and control. E-mail: basile.kawkabani@epfl.ch.
12 sessions, and each session being of four hours long.

The methodology used to teach the students is different from what is usually done. A goal is given and the students must manage to reach it by themselves. For a given test, they must investigate the theory by themselves, think of what and how must be measured, draw the connections of the different devices on a paper; including all the required measurement devices (oscilloscope, wattmeter, etc.) and only then perform the real test.

For example, if the student is asked to determine the inertia of the system, he first has to find how to determine it theoretically, which equations are involved, what conditions must be met during the test.

Then the student has to determine what must be measured (voltage, current, torque, speed?), and how to measure it. In the case of determining the inertia only the speed and torque need to be measured. He must then think of how to measure these values. In our example, how will the speed be measured? What is the output? Is it a voltage? What is the ratio between the speed and the voltage measured?

This approach usually helps the student to learn how to prepare testing sessions and get more confident with practical work as it is not a "let's try" 


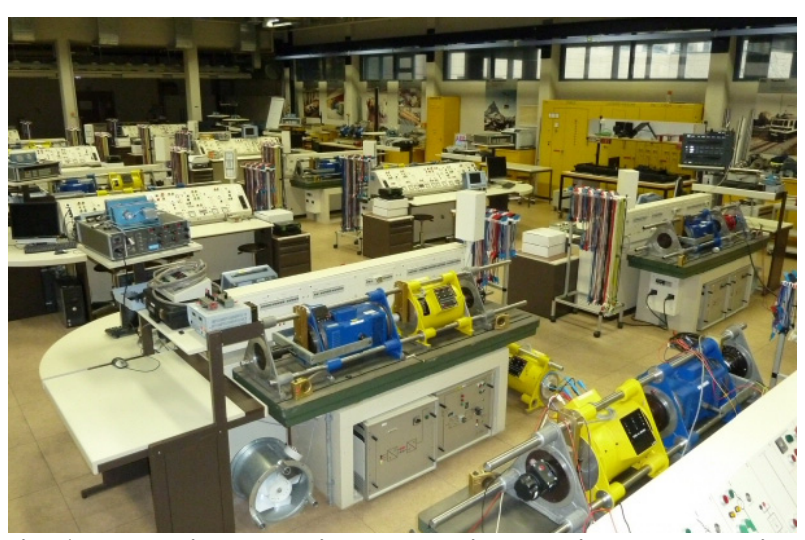

Fig. 1 Electrical machines and drives equipment, teaching lab facilities at EPFL.

approach, but a more methodological approach where everything is thought in advance and where the test is only the final step.

\section{Islanded Production Unit}

The advanced teaching lab presented here consists of setting up an islanding hydroelectric production unit of $\sim 3 \mathrm{kVA}$. Knowledge in measurement techniques, power electronics, control, electrical machines and network is required, explaining why this teaching lab is only given during the last semester of their studies (master level). Actually, the theoretical knowledge must be already understood as this teaching lab consists of gathering all those theoretical knowledge together in a practical work.

Many aspects are involved in setting up and testing such a production unit. The first one is the unit itself, which is constituted of a DC machine coupled to a synchronous generator (Fig. 2).

The method followed by the student to set up the production unit can be split into three major steps.

The first step consists of controlling the DC machine speed (Section 3), by means of power electronics (current converter) to regulate the frequency of the islanded network, such as a speed regulator would do in a "real" islanded hydroelectric production unit.

The second step consists of controlling the synchronous generator output voltage by means of an industrial voltage regulator (Section 5).

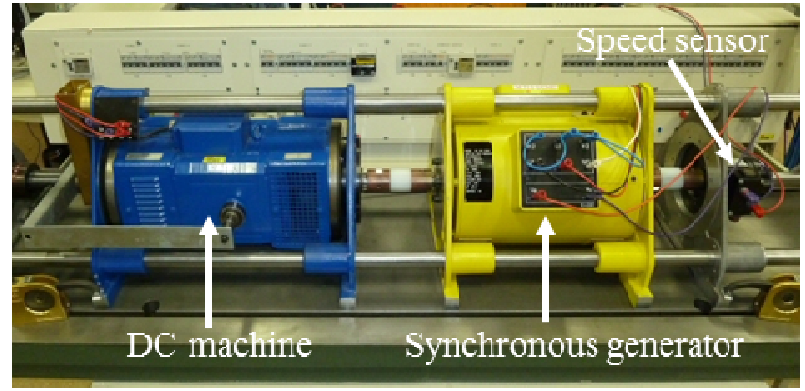

Fig. 2 Production unit.

An intermediate step, taking place just before the second step is presented in Section 4. It is not a required step to set up the islanded production unit but is helpful to the student to understand the behavior of the synchronous generator.

The third and last step consists of testing the unit under different loads and is presented in Section 6.

\section{DC Machine Speed Control}

The first step in setting up an islanded production unit is to control the speed of the unit, which in a real hydroelectric production unit is done by controlling the turbine torque. In the teaching lab presented here, the DC machine is used to simulate the turbine.

The DC machine used has the following characteristics. It is a DC machine with separate excitation:

- $1,800 \mathrm{~W}, 1,500 \mathrm{rpm}$

- $220 \mathrm{~V}, 10 \mathrm{~A}$;

- 0.8 A (field current).

Even though the rated current of the DC machine is $10 \mathrm{~A}$, for the control, the rated current is chosen at $5 \mathrm{~A}$. This is due to the fact that one wants to be able to regulate the system even under rated conditions. Therefore, expressed in per unit, the system can be controlled, in terms of current, in the range of $\pm 2 \mathrm{pu}$.

(a) DC machine torque control (current converter)

For controlling the DC machine torque, it is assumed that the student has already studied the DC machine in another teaching lab and knows that the torque of a DC machine, under a constant field current, is proportional to the armature current (1). Therefore, controlling the armature current allows controlling the 
torque.

$$
T=\mathrm{k} I_{f} I_{a}
$$

where, $T$ is the torque, $\mathrm{k}$ is a constant, $I_{f}$ is the field current and $I_{a}$ the armature current.

Here, it is important to explain that the bench used to supply the DC motor has an integrated current controller (Fig. 3), in which the set values can be remotely set by an analog voltage of $\pm 10 \mathrm{~V}$.

Hence, to control the speed, a cascaded control (Fig. 4) is used and the student only focuses on the speed control. However, to design the speed regulator, the student has to determine/measure all the small time constants of the internal current control.

(b) Cascaded control

The block diagram for the cascaded speed control is given in Fig. 4. As mentioned before it is a cascade control where the different transfer functions are:

- $G_{R i}(s)$ : transfer function of the current regulator;

- $G_{\mathrm{cm}}(s)$ : transfer function of the command;

- $G_{s a}(s)$ : transfer function of the armature current;

- $G_{R n}(s)$ : transfer function of the speed regulator;

- $G_{w a}(s)$ : transfer function of the internal control;

- $G_{s b}(s)$ : transfer function of the mechanical system.

(c) Internal current control (armature current)

The internal control of the armature current is given in Fig. 4a, and can be expressed as an equivalent transfer function $G_{w a}(s)$ which can be approximated by a 1 st order transfer function given by Eq. (2):

$$
G_{w a} \cong \frac{1}{1+s T_{e a}}
$$

where, $T_{e a}$ is given by Eq. (3):

$$
T_{e a}=2 T_{c m}
$$

and where $T_{c m}$ is the time constant of the control.

In our case, according to the current converter used (Fig. 3), $T_{c m}$ is defined as:

$$
T_{c m}=\frac{T}{12}=\frac{20 \mathrm{~ms}}{12}=1.67(\mathrm{~ms})
$$

The transfer function $G_{w a}(s)$ takes into account the delay of the internal control but does not take into account all the small time constants such as the sampling rate for example.

Therefore, $G_{w a}(s)$ is replaced by a transfer function of first order that includes all the small delays.

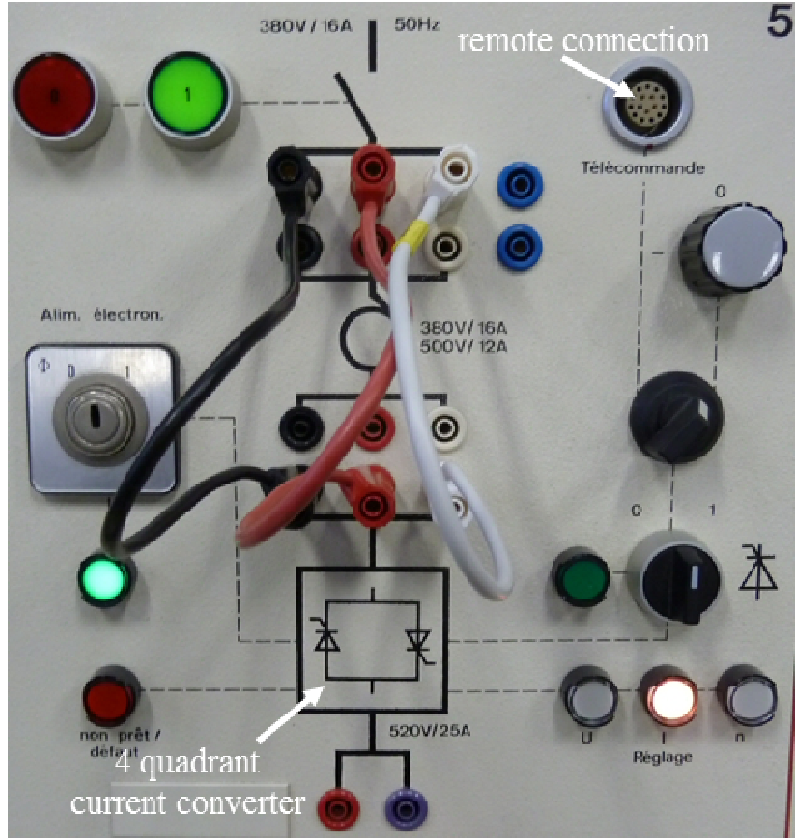

Fig. 3 DC machine armature current supply: (a) converter; (b) remote connection (set value).
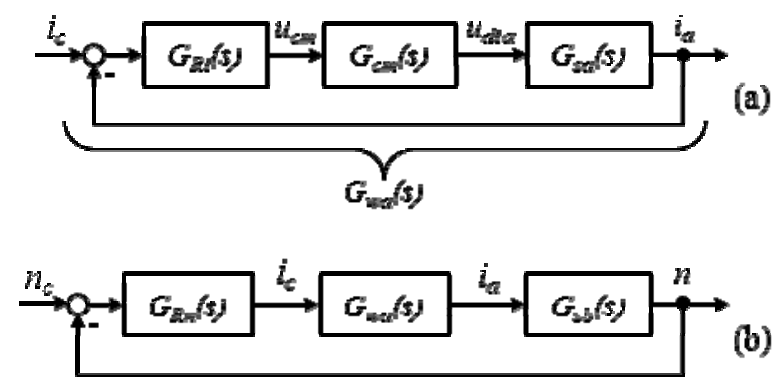

Fig. 4 Cascaded speed control: (a) internal current control; (b) speed control.

$$
G_{e q}=\frac{1}{1+s T_{p E}}
$$

with

$$
T_{p E}=T_{e a}+T_{r}+T_{s}
$$

where, $T_{s}$ is the sampling time constant and $T_{r}$ the time constant of the delay within the command. This latter can be determined by measuring the delay between the set value and the current.

Fig. 5 presents the measurement of $T_{r}$. The armature current is in blue, whereas the armature current set value is in magenta. Measuring the delay between the set value step and the effective time at which the current starts to rise gives $T_{r}$ ( $x$ in bottom right of Fig. 5). Averaging multiple measurements gives a value of $T_{r}$ : 


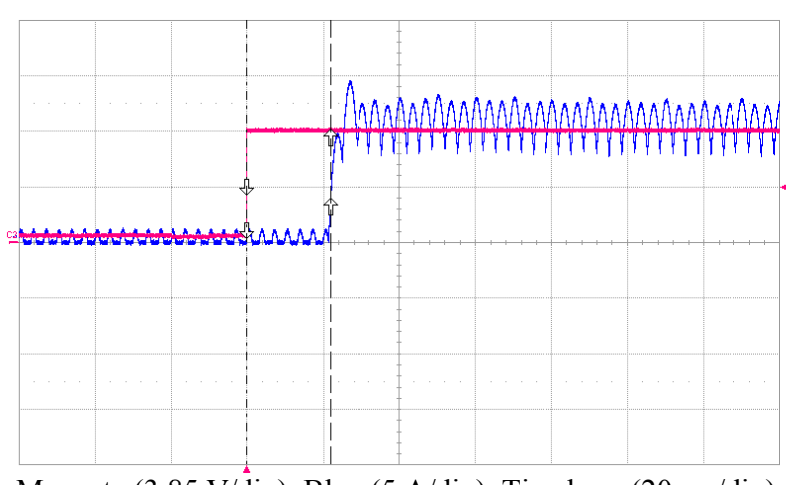

Magenta (3.85 V/div), Blue (5 A/div), Timebase ( $20 \mathrm{~ms} / \mathrm{div})$

Fig. 5 Measurement of $T_{r}$.

(d) Speed regulator

$$
T_{r}=22.4(\mathrm{~ms})
$$

The speed control is given in Fig. $4 \mathrm{~b}$, where $G_{w a}(s)$ has just been defined above.

The mechanical system $G_{s b}(s)$ to be regulated is of 1 st order with integral behavior and is given in Eq. (8):

$$
G_{s b}=\frac{1}{s T_{m}}
$$

The mechanical time constant $T_{m}$ is obtained by measuring the time needed to reach the rated speed $(1,500 \mathrm{rpm})$, starting at no speed $(0 \mathrm{rpm})$ and by applying the rated current.

Fig. 6 presents the measurement of $T_{m}$. The armature current is in blue, whereas the armature current set value is in magenta and the speed in yellow. The speed sensor used has a ratio of $0.06 \mathrm{~V} / \mathrm{rpm}$ $(1,500 \mathrm{rpm} \rightarrow 90 \mathrm{~V})$. Measuring the time needed to reach $90 \mathrm{~V}$ gives $T_{m}$ ( $x$ in bottom right of Fig. 6):

$$
T_{m} \cong 1.33(\mathrm{~s})
$$

Then, the closed loop transfer function for the speed control (Fig. 4b), including the PI regulator $G_{R n}(s)$, can be written:

$$
G_{b 0}=\frac{1+s T_{n}}{s T_{i}} \frac{1}{1+s T_{p E}} \frac{1}{s T_{m}}
$$

in the current case the Symmetrical Optimal Criterion [12] is applied and the time constants are given by:

$$
\left\{\begin{array}{l}
T_{n}=4 T_{p E} \\
T_{i}=8 \frac{T_{p E}^{2}}{T_{m}}
\end{array}\right.
$$

from this, the gain constants for the proportional and integral parts can be written in the digital world (using Padé approximation) :

$$
\left\{\begin{array}{c}
K_{p}=\frac{T_{n}-\frac{T_{s}}{2}}{T_{i}} \\
K_{i}=\frac{T_{s}}{T_{i}}
\end{array}\right.
$$

(e) Hardware implementation

The hardware used to perform the speed control is shown in Fig. 7. It is constituted of a computer with a PCI acquisition card which has analog to digital (A/D) and digital to analog (D/A) converters. The programming language is Pascal. Differential probes have to be used to adapt the voltage between the $A / D$ converter and the speed sensor (Fig. 2) respectively, the $\mathrm{D} / \mathrm{A}$ converter and the current set value remote connection (Fig. 3).

Fig. 8 shows the resulting Pascal code for the PI regulator with integrated limitation and error correction.

(f) Regulator behavior test

Finally, Fig. 9 presents the speed control behavior. The armature current is in blue, whereas the armature current set value is in magenta and the speed in yellow.

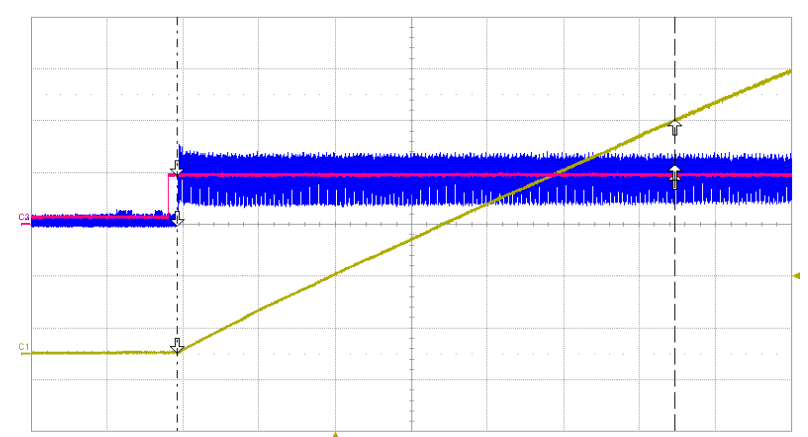

Yellow (20 V/div), Magenta (3.85 V/div), Blue (5 A/div), Timebase $(200 \mathrm{~ms} / \mathrm{div})$

Fig. 6 Measurement of $T_{m}$.

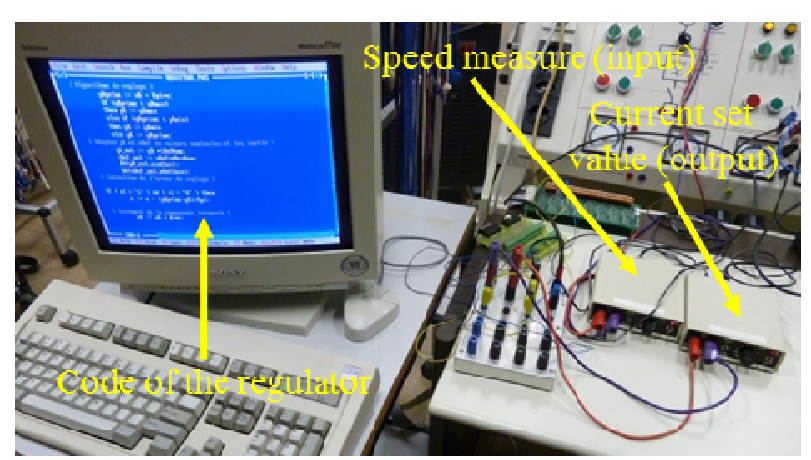

Fig. 7 Speed control hardware. 


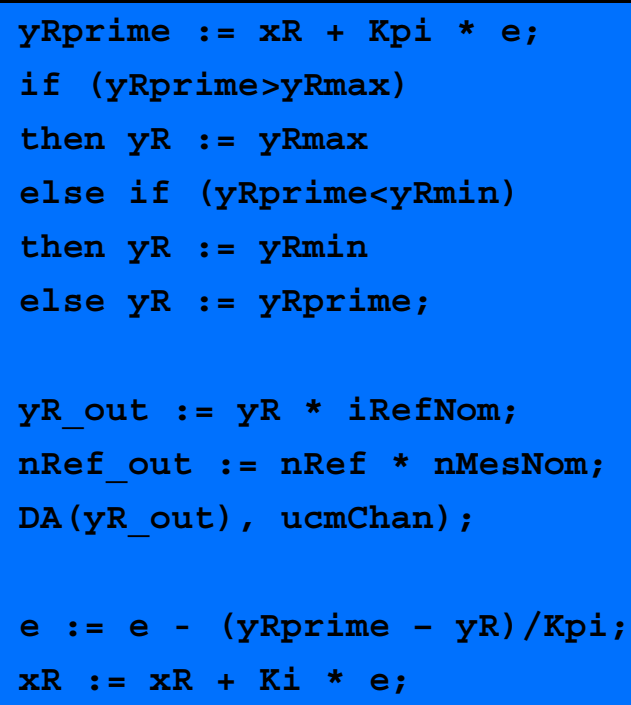

Fig. 8 PI regulator with integrated limitation and error correction.

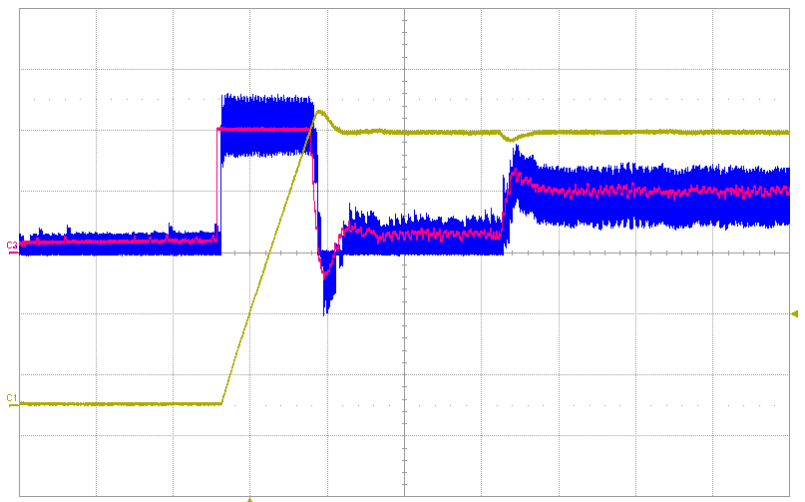

Yellow (20 V/div), Magenta (3.85 V/div), Blue (5 A/div), Timebase $(500 \mathrm{~ms} / \mathrm{div})$

Fig. 9 Speed control test.

For this test the synchronous generator is excited at its no load excitation current $\left(I_{f 0}\right) . I_{f 0}$ is the field current required to have the rated voltage under no load conditions.

The stator of the synchronous generator is connected through a switch to a resistive load which corresponds to the DC-machine rated load.

Starting at no speed ( $0 \mathrm{rpm})$, a set value of the rated speed $(1,500 \mathrm{rpm})$ is given to the system. The regulator applies the maximum available current to accelerate as fast as possible. The speed rises and quickly stabilizes at its given set value. As explained at the beginning of this section, the maximum current is $10 \mathrm{~A}(2 \mathrm{pu})$, whereas the rated current is $5 \mathrm{~A}(1 \mathrm{pu})$.
Then, the load (rated) connected to the synchronous generator is applied. During this transient the speed varies of less than $4 \%$ and as expected the current stabilizes at $5 \mathrm{~A}(1 \mathrm{pu})$.

\section{Synchronous Machine Connected to the Network}

Before using the synchronous generator in an islanded network it is important for the student to understand the behavior (power diagram) of the synchronous generator connected to the network and the different steps to follow to perform a correct synchronization.

The salient-pole synchronous generator used has the following characteristics:

- 2,300 VA;

- 1,500 rpm, $50 \mathrm{~Hz}$;

- $220 / 380 \mathrm{~V}, 6.1 / 3.5 \mathrm{~A}, \cos \varphi 0.8$;

- $24 \mathrm{~V}, 4.5 \mathrm{~A}$ (rotor).

(a) Out-of-phase synchronization $\left(-90^{\circ}\right)$

Even though the student has already theoretically studied how to synchronize a synchronous generator to the network, performing it in practice usually helps the student in understanding the different conditions to be fulfilled (same frequency, same voltage, same phase sequence and same phase).

Fig. 10 represents the stator currents (yellow, blue and magenta) and the field current (green) during an out-of-phase synchronization at about $90^{\circ}$. For this latter the stator currents reaches a peak value of $50 \mathrm{~A}$ (35 A RMS (root mean square)), which is 10 times the rated current $(3.5 \mathrm{~A})$. The field current reaches a peak value of $20 \mathrm{~A}$ which is about 4.5 times the rated current $(4.5 \mathrm{~A})$.

(b) Power diagram of the synchronous generator

Another didactic point is the representation/measurement of the capability limits of the synchronous generator (Fig. 11). This can be achieved by using a power meter which gives a voltage proportional to the active power and another voltage proportional to the reactive power. 


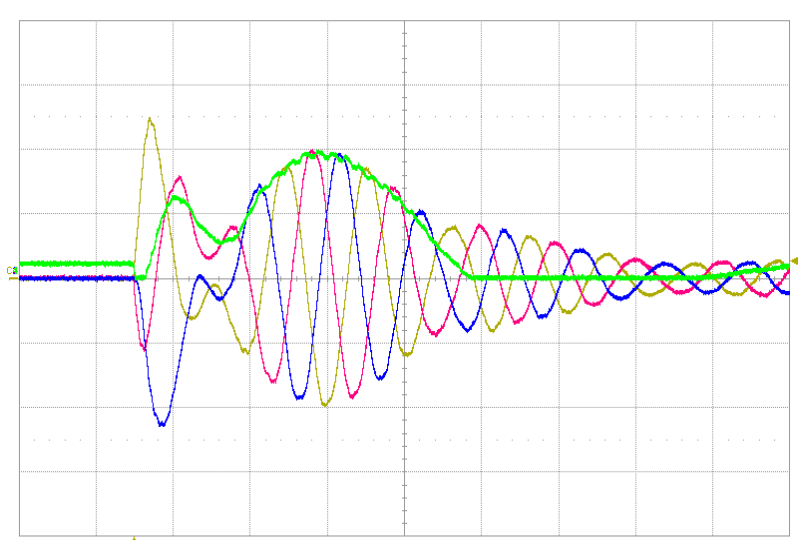

Yellow-Magenta-Blue (20 A/div), Green (10 A/div), Timebase ( $20 \mathrm{~ms} / \mathrm{div})$

Fig. 10 Currents during an out of phase synchronization at $-90^{\circ}$.

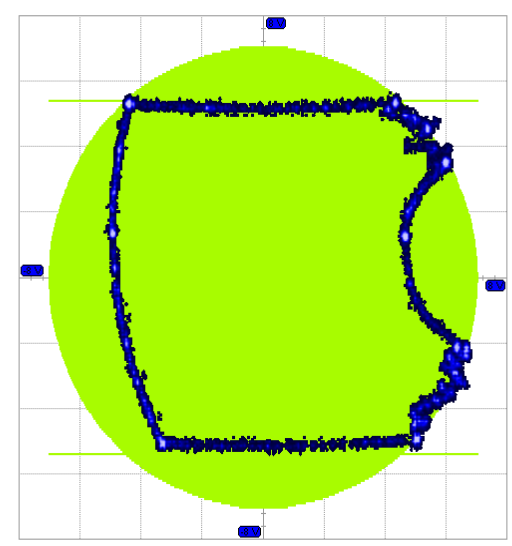

Fig. 11 Synchronous machine capability limits.

Then by plotting these voltages in X-Y mode with an oscilloscope (reactive power on the $x$ axis and active power on the $y$ axis), using the persistence and adding a "mask" in the background let us have a very pedagogical representation of the power diagram.

\section{Islanded \\ Generator-Unitrol ${ }^{\mathrm{TM}}$}

Synchronous

The next step to set up an islanded network is to use a voltage regulator to control the excitation current of the synchronous generator and regulate the voltage to a given value. In our case, a standard voltage regulator (Unitrol ${ }^{\mathrm{TM}}$ ) is used (Fig. 12).

To be able to use the software controlling the Unitrol $^{\mathrm{TM}}$, some parameters have to be determined, such as the direct-axis and quadrature-axis synchronous reactances.

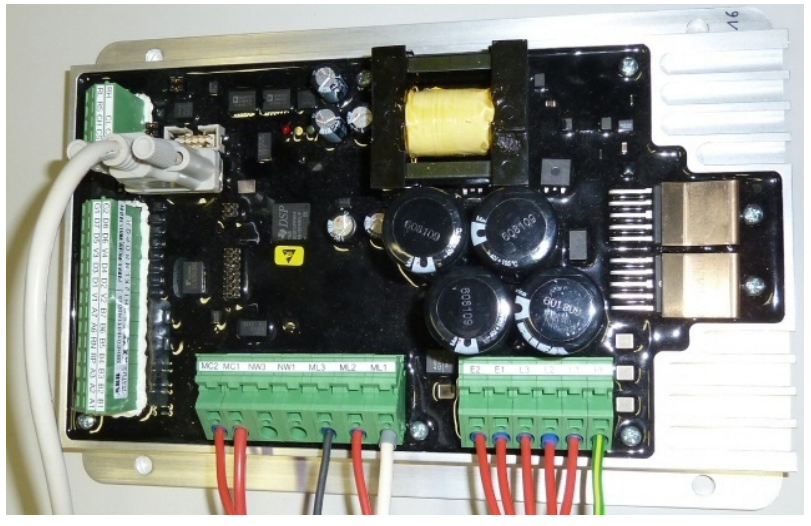

Fig. 12 Voltage regulator-Unitrol ${ }^{\mathrm{TM}}$.

Two different tests are performed to achieve this. The first one is a sudden 3-phase short-circuit and the second one is a negative excitation test. Note that these two tests are performed with the synchronous generator synchronized to the network. This emphasizes that previous chapter is relevant.

Note that for the sudden 3-phase short-circuit test, the transient and sub-transient reactances are determined by the student. This is only for teaching purposes as for using the software of the voltage regulator only $X_{d}$ and $X_{q}$ are required.

(a) Sudden 3-phase short-circuit

For the sudden 3-phase short-circuit, the synchronous generator is synchronized to the network. To avoid short-circuiting the network, a switch is used. The switch is connected to the synchronous generator and is wired as to be able to switch between a direct connection to the network and to cables that are short-circuited.

The stator phase currents during a sudden 3-phase short-circuit are shown in Fig. 13. Once the steady-state operating point is reached, the peak value of the phase current can be expressed as:

$$
i=\sqrt{2} \frac{U_{s 0}}{X_{d}}
$$

where, $U_{s 0}$ is the RMS value of the no load phase voltage, and $i$ the peak value of the steady-state short-circuit current, which in our case gives:

$$
X_{d}=\sqrt{2} \frac{220}{4.35}=71.5 \Omega
$$

(b) Negative excitation test

For the negative excitation test, the synchronous 


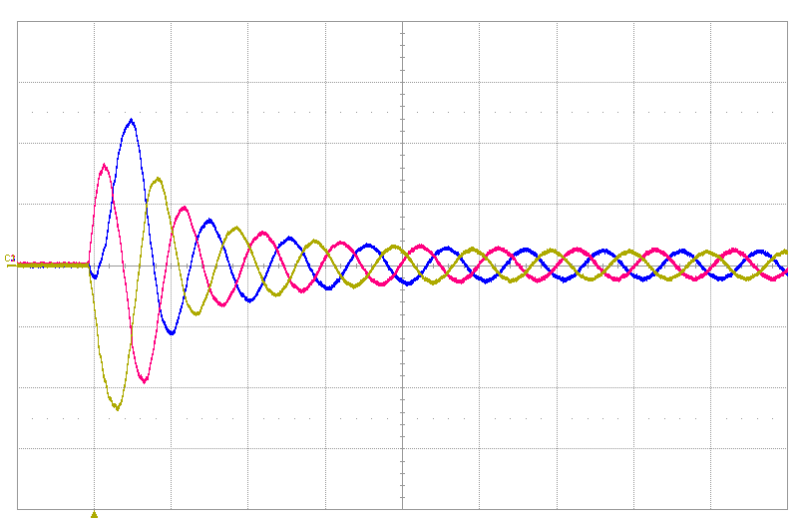

Yellow-Magenta-Blue (20 A/div), Timebase (20 ms/div) Fig. 13 Sudden 3-phase short-circuit.

generator is synchronized to the network. Then the excitation is decreased to 0 , the excitation wires are inverted and the excitation is raised until the generator loses the synchronism.

During this test, the phase current peak value is measured. At the moment of the loss of synchronism Eq. (13) can be used by replacing $X_{d}$ by $X_{q}$ :

$$
X_{q}=\sqrt{2} \frac{220}{14}=22.2 \Omega
$$

The oscilloscope screen copy for this test is given in Fig. 14, where the stator current of one phase is represented in yellow.

(c) Tuning the voltage regulator parameters

The software controlling the Unitrol ${ }^{\mathrm{TM}}$ must be installed on a Windows ${ }^{\mathrm{TM}}$ based computer. It does not only allow to start up the voltage regulation but it also gives access to many software based measurements such as PQ diagram, voltage and amper meters, synchronization diagram, oscilloscope, etc..

Once $X_{d}, X_{q}$ and all the required parameters (rated voltage, rated current, rated apparent power, etc.) are entered in the software, the tuning of the voltage regulator can be done.

Fig. 15 presents a screen copy of different windows comprising the Unitrol software. On the right hand side of this figure is the oscilloscope, whereas on the left hand side are the knobs to adjust the different parameters of the voltage regulator.

To tune the regulator, a change of $10 \%$ in the voltage set value is performed. In the oscilloscope of Fig. 15, the machine frequency is in blue, the excitation

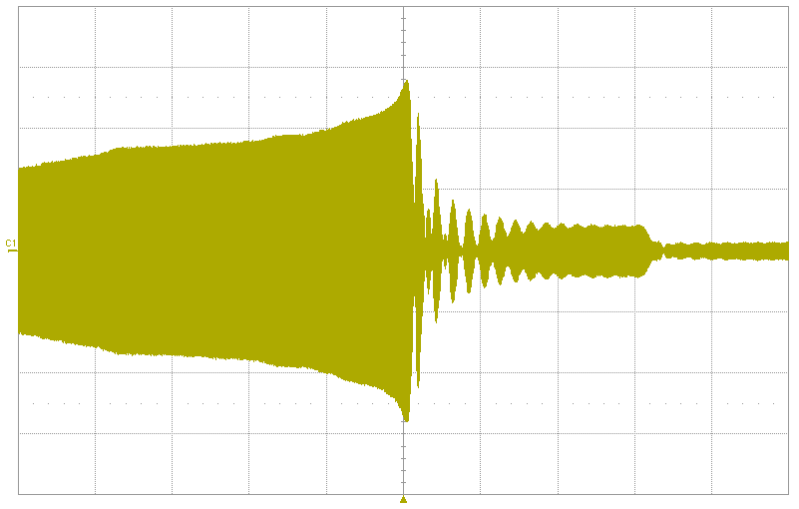

Yellow (5 A/div), Timebase (20 s/div)

Fig. 14 Negative excitation test.

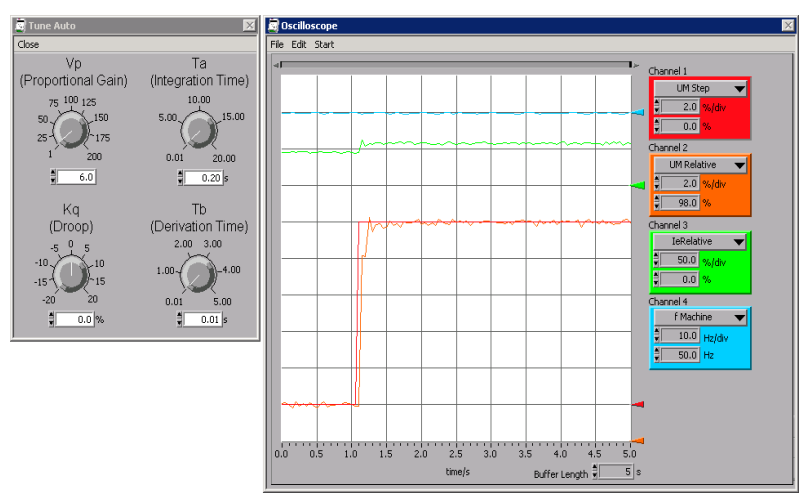

Fig. 15 Tuning the voltage regulator.

current in green, the voltage set value in red and the measured voltage in orange. After testing different values for $V_{p}, T_{a}$ and $T_{b}$ (knobs at the top left) to tune the voltage regulator, the values chosen give a correct response of the system to the voltage step. The response is fast, with no overshoot and no oscillation.

\section{Islanded Production Unit Tests}

In this section the production unit is tested under different loads. The first load is a pure resistive load, the second one is a pure capacitive load and the third one is the start up of an induction motor under no load conditions.

For all three tests, the production unit is started up, running at its rated speed $(1,500 \mathrm{rpm})$ and rated line voltage $(380 \mathrm{~V})$. The different three-phase loads are connected, through a switch, to the stator winding synchronous generator.

(a) Resistive load

The resistive load is constituted of a three-phase 
variable resistor (star connected) which value is set so as the DC machine generates an active power of $1 \mathrm{pu}$ which in our case corresponds to the rated current ( 5 A, see Section 3f).

In Fig. 16, the voltage is in red, the speed in green and the excitation current in orange.

During the transient, the voltage drop is about $4 \%$ and the frequency drop about $5 \%$. The system stabilizes in less than $200 \mathrm{~ms}$.

An interesting pedagogical point is that as the load is purely resistive, a student could expect to have only the speed regulator reacting to the load step. However, the voltage regulator must compensate the voltage drop in the synchronous generator winding by increasing the excitation current.

(b) Capacitive load

The capacitive load is constituted of a bench of variable capacitors (star connected). The capacitors value is set to $17 \mu \mathrm{F}$ (per phase). Beyond this value, the excitation current is too small and the system becomes unstable.

In Fig. 17, the voltage is in red, the speed in green and the excitation current in orange.

During the transient, the frequency is nearly not affected by the load change (1\%). This small variation is due to the internal resistance of the bench of capacitors as well as the stator resistance of the synchronous generator that will dissipate active power that must be compensated by the speed regulator.

The voltage increase is about $5 \%$ and the system stabilizes in less than $200 \mathrm{~ms}$.

(c) Induction motor (no load)

The final test consists of starting up an induction motor, under no load conditions. The induction motor used is a single cage induction motor with the following characteristics:

- 2,200 W, 1,435 rpm, $50 \mathrm{~Hz}$;

- $220 / 380 \mathrm{~V}, 8.7 / 5.0 \mathrm{~A}, \cos \varphi 0.79$.

This test implies that both regulators react (speed and voltage) to deliver not only the active power to start up the induction motor but also reactive power.

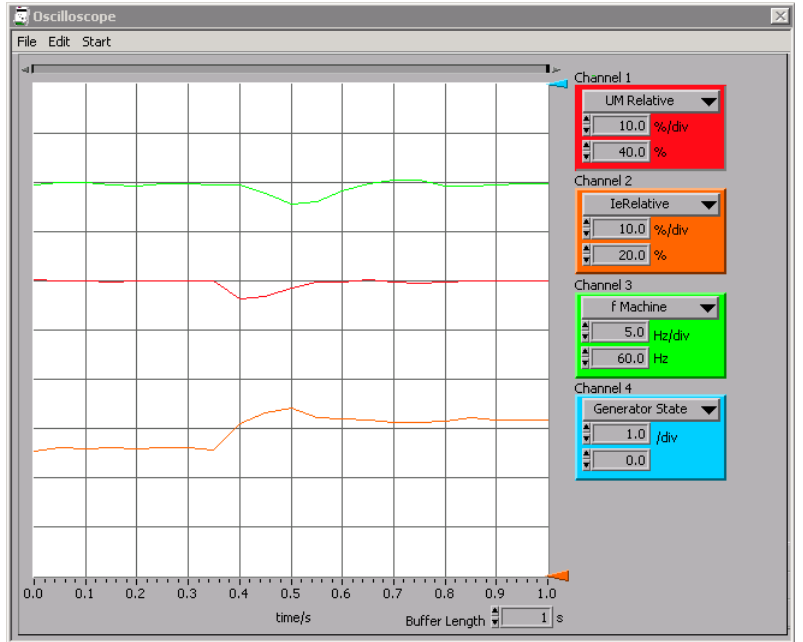

Fig. 16 Resistive load test.

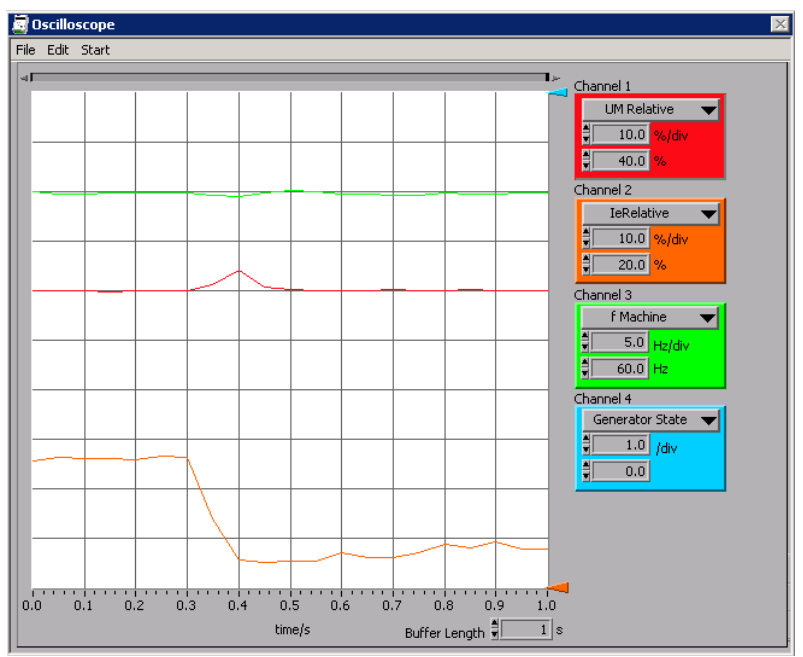

Fig. 17 Capacitive load.

The oscilloscope screen copy for this test is given in Fig. 18, where the speed (frequency) and voltage of the islanded network are respectively in yellow and blue, whereas the speed of the induction motor in magenta.

The speed of the induction motor rises until it reaches the steady state conditions. Note that as the induction motor is under no load conditions the slip is nearly 0 when the steady state is reached.

During the transient, a large drop is found in both the frequency and the voltage. The frequency drop is about $13 \%-14 \%$, whereas the voltage drop is about $65 \%$. Even though these drops are large the system once again corrects this in about $200 \mathrm{~ms}$ and fully stabilizes in less than $500 \mathrm{~ms}$. 


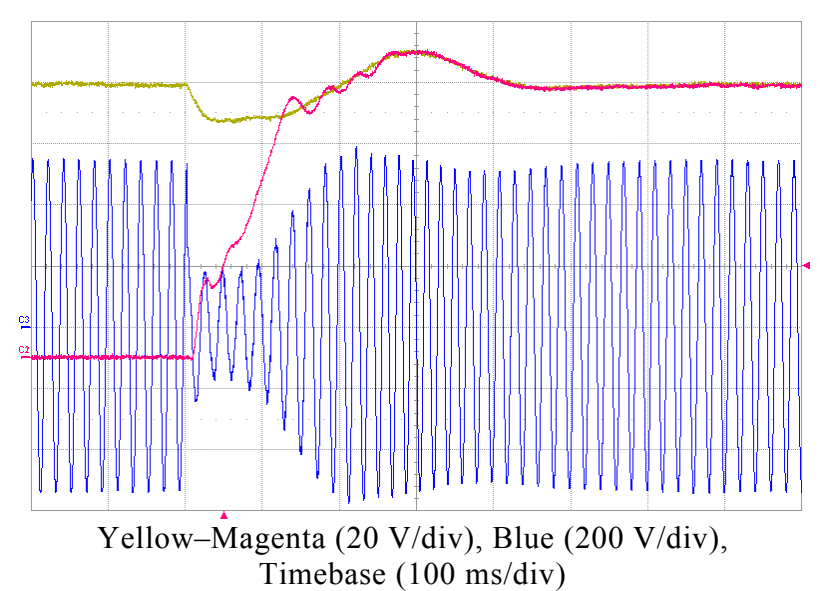

Fig. 18 Induction motor start up.

\section{Conclusions}

An advanced teaching lab consisting of setting up an islanded production unit has been presented.

The teaching technique used in this lab has been described, whereas the required steps to be followed have been explained in details.

The speed control of the DC machine as well as the voltage regulation have been detailed and illustrated by many oscilloscope or screen copies.

Other tests addressing the interconnection of multiple production units are also performed by the students in the teaching lab. These tests allow the study of the different power exchanges (active and reactive) between the different production units and their loads (resistive, capacitive and induction motor).

\section{References}

[1] E.R. Collins, An energy conversion laboratory using industrial-grade equipment, IEEE Transaction on Power Systems 24 (1) (2009) 3-11.

[2] G. Venkataramanan, A pedagogically effective structured introduction to electrical energy systems with coupled laboratory experiences, IEEE Transaction Power Systems 19 (1) (2004) 129-138.

[3] K.A. Corzine, M.L. Crow, Power engineering laboratory facilities at the University of Missouri-Rolla, in: Proceedings of 2005 IEEE Power Engineering Society General Meeting, USA, June 12-16, 2005, pp. 1187-1191.

[4] R.S. Balog, Z. Sorchini, J.W. Kimball, P.L. Chapman, P.T. Krein, Modern laboratory-based education for power electronics and electric machines, IEEE Transaction Power Systems 20 (2) (2005) 538-547.

[5] R.C. Panaitescu, N. Mohan, W. Robbins, P. Jose, T. Begalke, C. Henze, et al., An instructional laboratory for the revival of electric machines and drives courses, in: Proceedings of 33rd IEEE Power Electronics Specialists Conference, USA, June, 2002, pp. 455-460.

[6] S.P. Carullo, C.O. Nwankpa, Interconnected power systems laboratory: A computer automated instructional facility for power system experiments, IEEE Transaction Power Systems 17 (2) (2002) 215-222.

[7] C. Nwankpa, K. Miu, D. Niebur, X. Yang, S.P. Carullo, Power transmission and distribution system laboratories at Drexel University, in: Proceedings IEEE Power Engineering Society General Meeting, USA, June 12-16, 2005, pp. 1198-1205.

[8] T.W. Gedra, S. An, Q.H. Arsalan, S. Ray, Unified power engineering laboratory for electromechanical energy conversion, power electronics, and power systems, IEEE Transaction Power Systems 19 (1) (2004) 112-119.

[9] S. Ray, S. An, T.W. Gedra, Introduction of power electronics to electric machines lab, in: Proceedings of 45th Midwest Symposium Circuits and Systems, USA, Aug. 4-7, 2002, pp. 383-386.

[10] P.W. Sauer, G.T. Heydt, V. Vittal, The state of electric power engineering education, IEEE Transaction on Power Systems 19 (1) (2004) 5-8.

[11] Software package Simsen Home Page, http://www.epfl.ch.

[12] J.W. Umland, M. Safiuddin, Magnitude and symmetric optimum criterion for the design of linear control systems: what is it and how does it compare with the others?, IEEE Transaction on Industry Application 36 (3) (1990) 489-497. 